\title{
PHENETIC RELATIONSHIPS IN THE GENUS MYOTIS ${ }^{1}$ )
}

\author{
by
}

\author{
JAMES S. FINDLEY \\ Department of Biology, University of New Mexico, Albuquerque, New Mexico, U.S.A.
}

The genus Myotis is of interest to the evolutionist because of its diversity and because of its nearly cosmopolitan distribution. An understanding of the biology of this remarkable genus may provide insight into its success, as well as the success of other expansive groups of mammals. As part of an overall study of Myotis, I subjected measurements of 48 morphological traits from most of the described species to standard numerical taxonomic analysis. I hoped to delineate phenetic groupings in the genus, and to learn if these groupings provide insight into adaptive diversification of species, into the history of the genus, and into a replicable approach to its classification.

Phenograms based on Pearson product-moment correlation coefficients and on coefficients of taxonomic distance were prepared, as was a three dimensional model depicting phenetic placement of the species with respect to the first three principal factors derived from a centroid factor analysis. The analysis was performed using the Numerical Taxonomy System of Multivariate Statistical Programs (NT-SYS) developed by F. James Rohlf, John Kishpaugh, and Ron Bartcher, at the University of Kansas in 1968. For methodology, see especially Sokal \& Sneath, 1963, and Rohlf, 1968.

Examination of the correlation phenogram (fig. 1) reveals that this approach divides the genus into three major groupings. Here each name may stand for a grouping of a number of currently recognized species. The top group includes (1) the traditional members of the subgenus Leuconoe, (2) the big-footed Pacific basin forms stalkeri, macrotarsus, and vivesi (within "adversus"), (3) M. ricketti, usually placed in a distinct subgenus, Rickettia (within "adversus"), (4) the members

$\left.{ }^{1}\right)$ Study supported by a grant from the National Science Foundation. of the $M$. siligorensis group, placed by Tate (1941) and others in the subgenus Selysius, (5) a group of American species, most of which were placed in

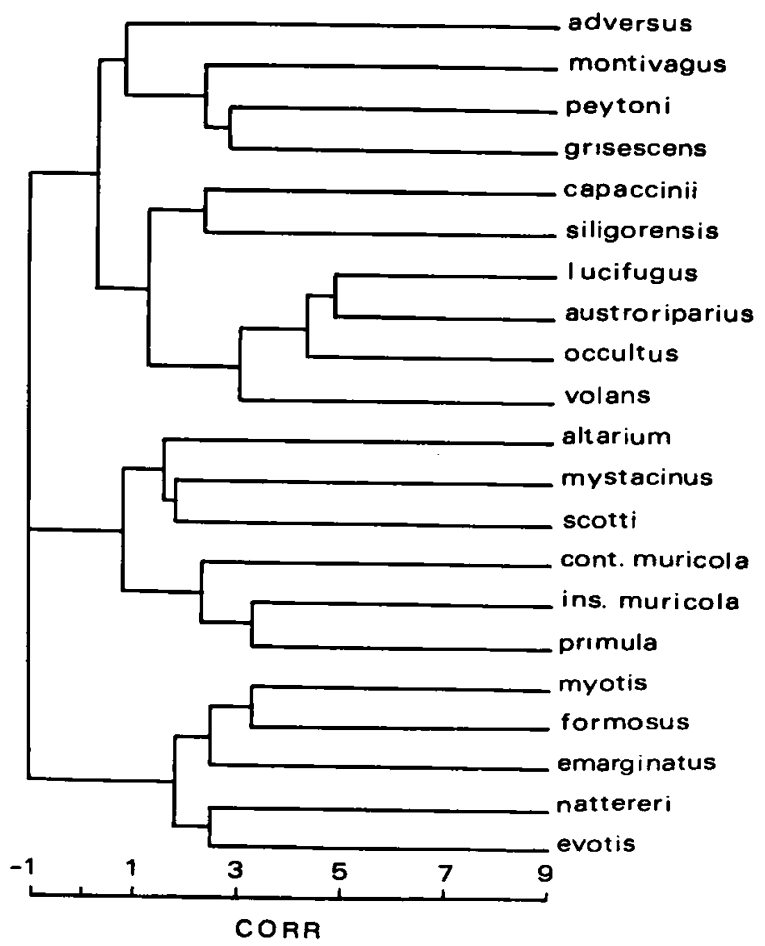

Fig. 1. Correlation phenogram for myotine taxa. Higher numbers indicate greater similarity. Many of the names stand for groups of similar species as follows: adversus (bocagei, adversus, peshwa, stalkeri, vivesi, macrotarsus, dasycneme, ricketti); montivagus (simus); peytoni (federatus, fortidens); grisescens (velifer, chiloensis); capaccinii (daubentoni, fimbriatus, macrodactylus, longipes, taiwanensis); siligorensis (insularum); lucifugus (yumanensis, albescens); mystacinus (californicus, leibii); continental muricola ("caliginosus," "blanfordi," moupinensis, sodalis, nigricans); insular muricola (ater, latirostris); myotis (bech. steini, blythi, sicarius); formosus (welwitschii); emarginatus (goudoti, tricolor); nattereri (pequinius, thysanodes); evotis (auriculus, keenii). 
Selysius by Tate, and (6) the African M. bocagei. These taxa have in common relatively large feet, short legs and wings, relatively large size, relatively hairy membranes and legs, and strong development of accessory molar cusps, and poorly developed calcarial keel.

The middle group consists of traditional members of the subgenus Selysius, including the African scotti, and several small American species. These animals are characterized by small size, long appendages, small feet, relatively short dentaries with low coronoid processes, weakly developed temporal muscles, well developed calcarial keel, and extensive uropatagium which is well haired ventrally.

The bottom group consists of the members of the classical subgenera Myotis, Chrysopteron, Isotus, and Paramyotis. These taxa are characterized by larger size, long appendages, small feet, long, forward-directed ears, large skull, long jaws, high coronoid process, strong temporal muscles, reduced secondary molar cusps, reduced upper third molars, increased complexity of lower incisors, and relatively long wings.

The stereogram, two views of which are seen in

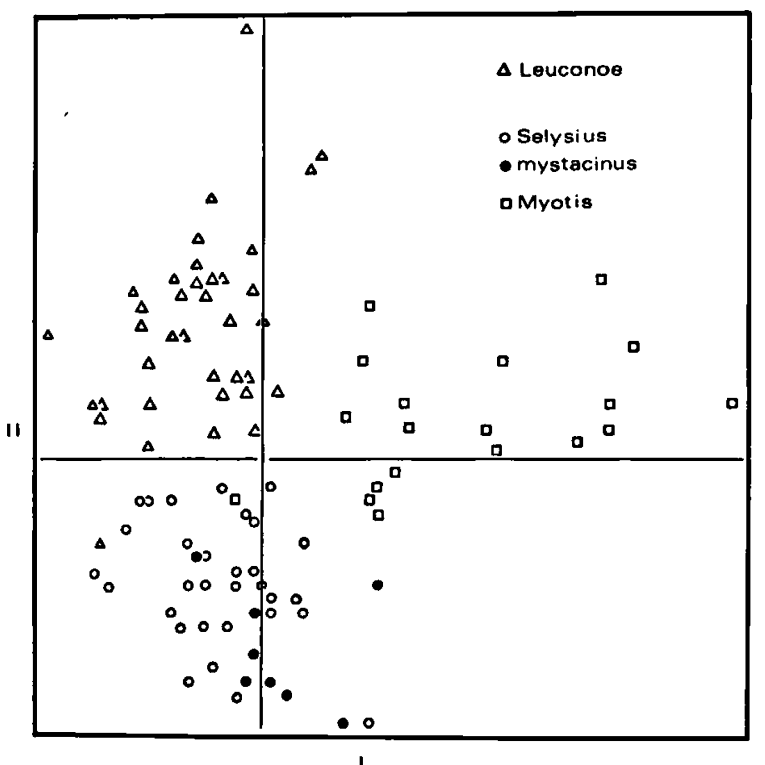

Fig. 2. Plan view of stereogram based on first two factors from a centroid factor analysis. Progression to the right involves longer appendages, larger, more forwardly directed ears, more sectorial molars, and increased size. Progression upwards involves shorter wings and legs, bigger feet, hairier tibiae, and reduction in calcarial keel. Symbols allocate taxa to subgenera as suggested in the text. $M$. siligorensis is included in Selysius.

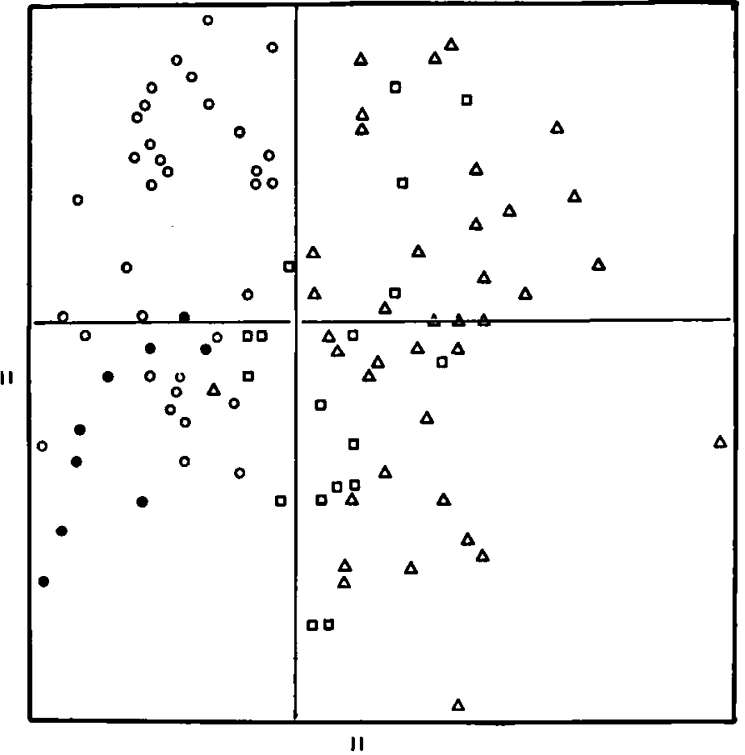

Fig. 3. Side view of stereogram. Progression upward involves narrower wings and less hairy membranes.

figs. 2 and 3, depicts these species groups in three dimensions. Each axis represents a composite of correlated traits, and each point stands for one operational taxonomic unit (OTU). Taxa high on Factor I are those in the bottom group on the correlation phenogram, taxa high on Factor II are those of the top group from the correlation phenogram, and taxa low on I and II comprise the middle group. The principal difference from the correlation phenogram is in the grouping of siligorensis and volans with this middle group. The third factor of the factor analysis is not heavily involved with many traits. Bats high on this scale have longtipped narrow wings, less hairy membranes, less countershading, and less wooly hair than those low on the scale. These traits seem especially useful for distinguishing the muricola and mystacinus groups. Many of the bats high on this scale are tropical or subtropical, and many are insular. These two factors seem to me to account for the scantier less wooly hair and the higher aspect ratio wings respectively.

These two devices seem to reinforce the concept of three major morphological groupings, which might be designated by the subgeneric terms Leuconoe, Selysius, and Myotis. Most distinctive is Myotis which seems to me likely to be specialized for relatively slow maneuverable flight (long. broad wings), for detection of prey located immediately in front of the animal (large, forward- 
directed ears), and perhaps for picking prey from various substrata such as vegetation or the ground (long jaws and complex incisors). The simplified sectorial molars and well developed temporals seem likely to be an adaptation to slicing especially obdurate prey.

Leuconoe seems adapted to rapid direct flight (short wings), and perhaps to frequent use of the feet in the capture of prey. Several members of this group are known to be piscivorous, and it may be that many gaff prey from the surface of the water.

Selysius appears well adapted to aerial pursuit and capture of small insects which may frequently be "netted" in the interfemoral membrane with its well developed ventral "trap" of medially directed hairs.

The distance phenogram (fig. 4) reveals many of the same groupings seen in the other diagrams, but emphasized the isolated position of many taxa,

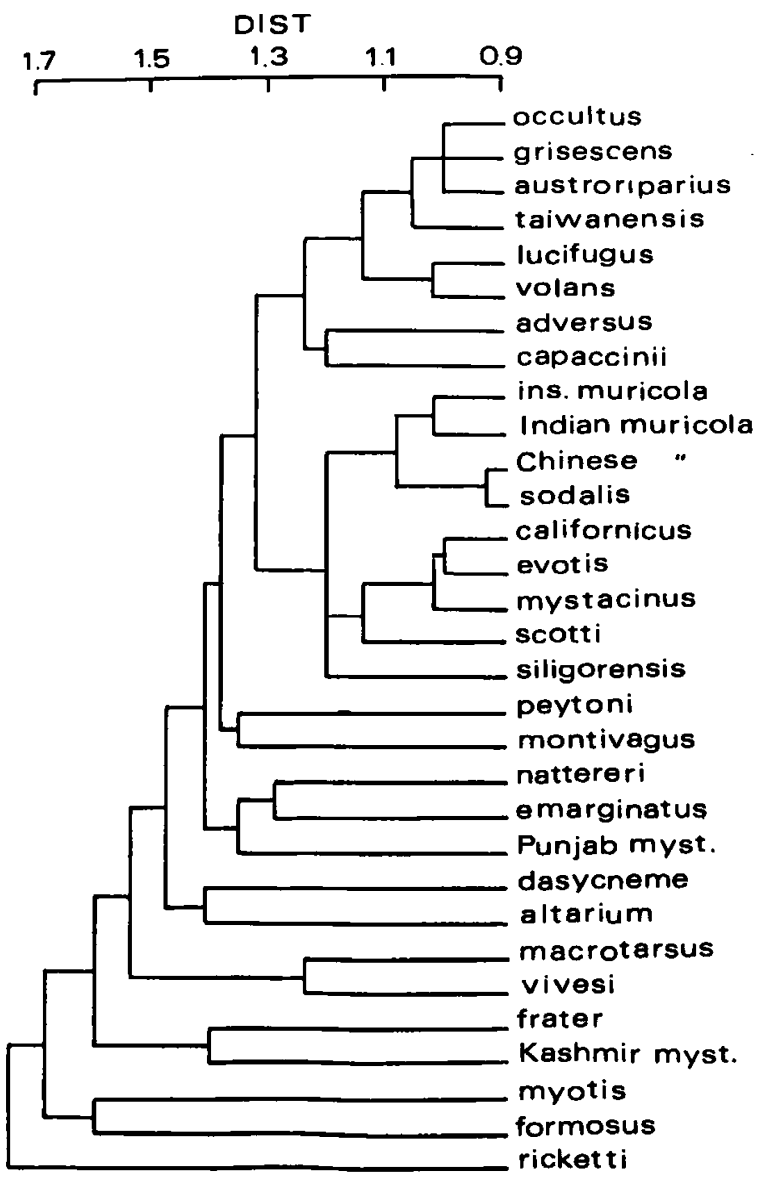

Fig. 4. Phenogram based on taxonomic distance. The higher numbers indicate greater distance.

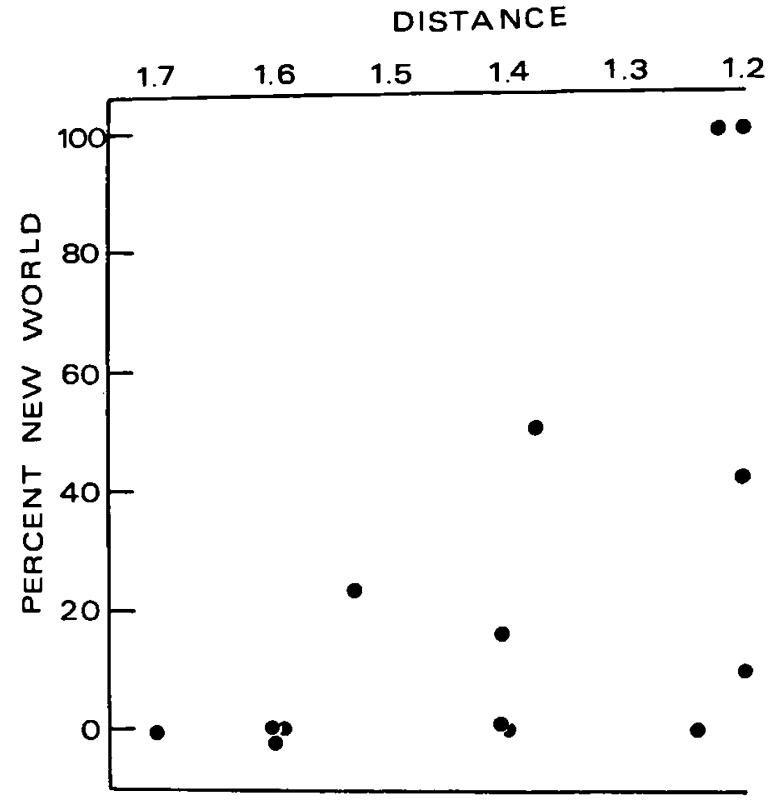

Fig. 5. Taxonomic isolation of each group of species, as indicated by each group's distance from the nearest other group, plotted against percent of species within each group occurring in the New World.

and differs from the correlation phenogram most notably in aligning the evotis and siligorensis groups with the mystacinus complex.

When the degree of distance which each group of species shows with its nearest neighbors is plotted against the percent of taxa in each group which are of New World occurrence (fig. 5), it is seen that few distinctive taxa of Myotis occur in the western hemisphere, but that a number of clusters of similar species are found there. I interpret this to mean that Myotis has been evolving for a longer period of time in the Old World than in the New, and that most of the New World species have arisen from relatively few immigrants.

Those species of Myotis which would have to be modified least to give rise to any other existing species might be thought to be most like a hypothetical ancestor. It is therefore interesting to note that the most nearly central species on the three dimensional stereogram is $M$. goudoti from Madagascar, home of so many ancient stocks of mammals.

\section{CONCLUSIONS}

1. Numerical taxonomic results suggest the existence of three major groupings of species to which 
the subgeneric names Myotis, Selysius, and Leuconoe might be applied.

2. Each grouping is composed of species which are distinctively modified in such a way as to suggest the existence of three major feeding-foraging patterns in the genus.
3. Analysis of taxonomic distance suggests the center of myotine evolution is the Old World.

4. One line of reasoning suggests that the ancestral Myotis is most closely approximated by Myotis goudoti of Madagascar.

\section{REFERENCES}

RoHLF, F. JAMES, 1968. Stereograms in numerical taxonomy. Syst. Zool., 17 : 246-260.

Sokal, R. R. \& P. A. Sneath, 1963. Principles of numerical taxonomy: 1-359 i-xvi. (W. H. Freeman and Co., New York and London).
TATE, G. H. H., 1941. Review of the genus Myotis (Chiroptera) of Eurasia, with special reference to species occuring in the East Indies. Bull. Amer. Mus. nat. Hist., 78 (8): $537-565$. 